\title{
Development of components for creation of the infrared module with the purpose of express analysis of motor-car fuel
}

\author{
A.V. Chernyaev ${ }^{1}$ \\ Microsensor Technology, LLC \\ Kurchatova str., 10, A, 1N, 194223, Saint Petersburg, Russian Federation \\ E-mail: chernyaevaveyandex.ru
}

\section{S.S. Kizhaev, B.E. Zhurtanov, K.V. Kalinina, N.D. Stoyanov}

Microsensor Technology, LLC

Kurchatova str., 10, A, 1N, 194223, Saint Petersburg, Russian Federation

E-mail: infoelmsnt.com

\section{Kh.M. Salikhov}

Institute of Perspective Researches, Tatarstan Academy of Sciences

Levo-Bulachnaya str., 36a, 420111 , Kazan', Russian Federation

E-mail: hafizmsemail.ru

\section{T.V. Stoyanova}

National Mineral Resources University (Mining University)

21 line of Vasil 'evsky Island, 2, 199106, Saint Petersburg, Russian Federation

E-mail: stoyanova_tvelist.ru

\begin{abstract}
Possibility of smart infrared (IR) module for express analysis of motor-car fuel was studied. Transmission spectra of different types of motor-car diesel fuel and petrol were measured using light emitting diodes (LEDs) and photodiodes (PDs) operating in the IR spectral range (1.3-3.6 $\mu \mathrm{m})$. Spectral particularities of different petrol brands were observed at wavelengths of 2.7 - 3.0 $\mu \mathrm{m}$. Diode parameters and their applicability for petrol/ diesel analysis were investigated. Epitaxial layers growth conditions were optimized for the improvement of the photodiode key operating parameters. Obtained results demonstrate the ability of using IR LEDs matrices and PDs for petrol/ diesel analysis purposes.
\end{abstract}

International Conference on New Photo-detectors

PhotoDet 2015

6-9 July 2015

Moscow, Troitsk, Russia

${ }^{1}$ Speaker 


\section{Introduction}

Development of low-cost portable sensors for the constant control of the fuel quality is a very important task. Such sensors may be of interest both for car owners and manufacturers of automobile engines, as the life of an engine depends on the fuel quality. In particular, the negative impact on engine renders the presence of water in the fuel. One possible solution of this problem is the development of an infrared module to analyze the composition of petrol and diesel fuel.

This paper reports on the investigation of IR radiation transmission in the range (1 - 4) $\mu \mathrm{m}$ through different petrol and motor-car diesel fuel samples. Particularities of the IR radiation transmission spectra have been identified.

\section{Spectra}

Transmission spectra (see fig.1a) reveal a number of relatively wide absorption lines, with the areas of total-absorption. Absorption bands of diesel fuel were shifted a bit to longer wavelengths comparing to petrol absorption bands. In the range $1.8-2.2 \mu \mathrm{m}$ diesel fuel showed a bit lower transmission of IR radiation than petrol. Difference in the transmission spectra of different petrol brands can be identified at wavelengths $2.7-3.0 \mu \mathrm{m}$. Reduction of transmission with the increase of octane number might be related to the amount of additives necessary to avoid detonation during fuel burning.

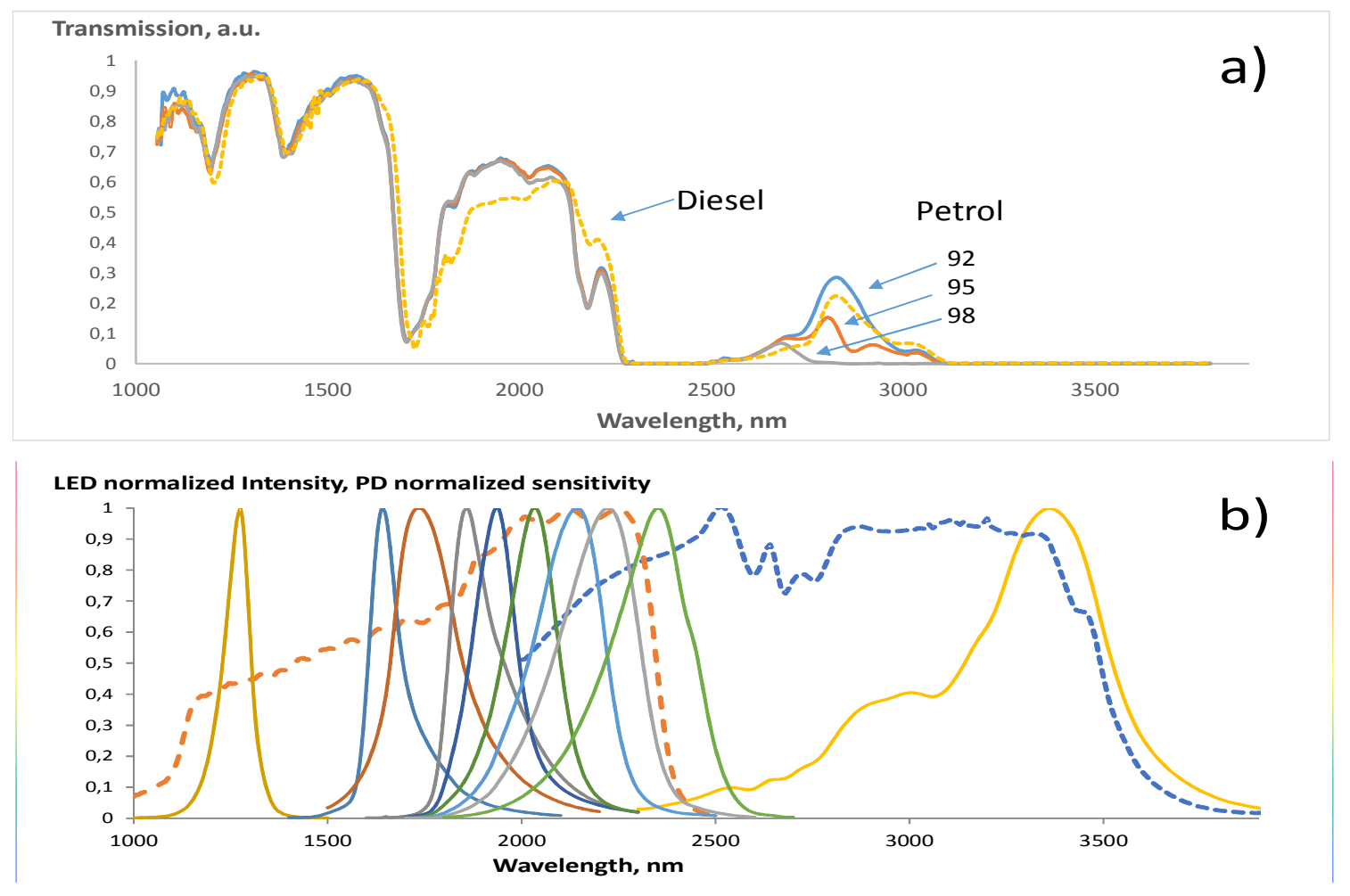

Figure 1: a) Transmission spectra of petrol (brand of the gasoline is indicated on fig.) and diesel fuel (dotted line). b) LED electroluminescence spectra (solid lines), photosensitivity spectra of the PD with a cut-off wavelength $2.4 \mu \mathrm{m}$ (dashed line) and $3.6 \mu \mathrm{m}$ cut-off (dotted line). 
High efficient light-emitting diodes (LEDs) and photodiodes (PDs) [1] are necessary for development of the smart IR module for the express analysis of petrol and diesel fuel. Previously we reported on the development of GaSb-InAs-based LEDs operating in the IR range [2, 3]. LED spectra operating in the range 1.6-2.3 $\mu \mathrm{m}$ are presented on fig1b. These LEDs can be used for petrol or diesel fuel analysis (see fig.2). LED spectrum width (FWHM) is about $200-450 \mathrm{~nm}$, output optical power is up to $2 \mathrm{~mW}$. High sensitive GaSb-InAs-based PDs operating in the range $1.0-2.4 \mu \mathrm{m}$ (fig.1b) were developed. Parameters of the PDs with cut-off wavelength about $2.4 \mu \mathrm{m}$ are as follows: responsivity $\mathrm{R}=1.4 \mathrm{~A} / \mathrm{W}$ (at wavelength $2.2 \mu \mathrm{m}$ ), resistivity (at no bias) $\mathrm{R}_{0}=6.0 \mathrm{kOhm}$, detectivity $\mathrm{D}^{*}=3.5 \times 10^{10} \mathrm{~cm} \sqrt{\mathrm{Hz}} / \mathrm{W}$, dark currents $\mathrm{I}=30 \mu \mathrm{A}$ (at reverse bias $1 \mathrm{~V}$ ), capacity $\mathrm{C}=0.40 \mathrm{nF}$.

\section{Petrol analysis using optical cell}

Transmission measurements of petrol samples were performed (fig.2). Six-element LED matrix with peak wavelengths $1.3,1.6,1.9,2.0,2.2,2.3 \mu \mathrm{m}$ was developed, matrix peak wavelengths are indicated on the horizontal scale of the fig.2. First measurement was done without any sample, with empty sample glasses, which were fixed in the optical cell, perpendicular to the emission direction between emitter and receiver. Transmission signal obtained through the sample glasses was taken as $100 \%$. Then, a drop of A92 petrol was placed between two glasses and it's transmission was measured (fig.2a). Fig.2b shows transmission of the same petrol sample with 5\% water content. Water-petrol sample was prepared by mixing of 19 drops of petrol one drop of water and stirring them for a few minutes (about 4 minutes). Signal level, in general, depend on the emission absorption by the components of the mixture (water, fuel) and on the scattering at boundaries water - fuel. Signal reduction at the wavelength $1.3 \mu \mathrm{m}, 1.6 \mu \mathrm{m}$ and $2.3 \mu \mathrm{m}$ is defined by petrol absorption (fig.2a). Signal decrease at $1.9 \mu \mathrm{m}$ and $2.0 \mu \mathrm{m}$ is related to water absorption when it is added to the petrol (fig.2b). More intensive signal reduction at $1.3 \mathrm{mkm}, 1.6 \mathrm{mkm}$ and $2.3 \mathrm{mkm}$ that was observed for the mixture of petrol with water (fig.2b) can be explained by the influence of scattering at water - petrol boundaries. Some increase of reflection coefficient $\mathrm{R}$ (in accordance with Fresnel dependence) at the boundary glass - fuel compared with the $\mathrm{R}$ at the boundary glass - air was taken into account.

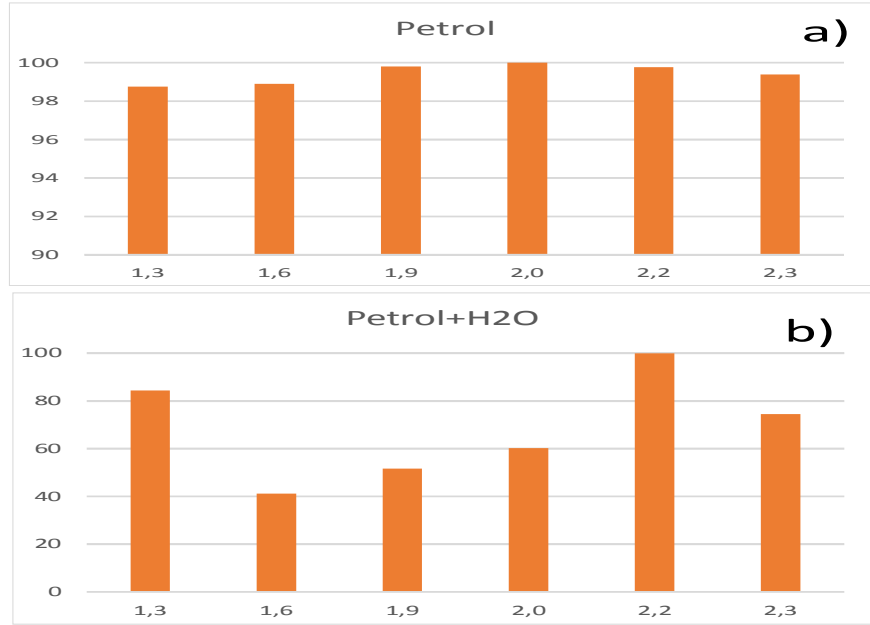

Figure 2: A92 petrol tansmission analysis results. a) glasses with a petrol sample without water. b) glasses with a petrol sample with $5 \%$ water content. 


\section{Photodiodes}

For the petrol analysis purposes photodiodes operating in the range $2.0-3.6 \mu \mathrm{m}$ at temperatures up to $60^{\circ} \mathrm{C}$ with the sensitive area diameter of $0.5 \mathrm{~mm}$ were developed. Two layers were deposited on the $\mathrm{n}$ - InAs substrate by metalorganic chemical vapour deposition. Thickness of the active area of $\mathrm{n}$ - InAs was $2.5 \mu \mathrm{m}$, of the barrier layer of $\mathrm{p}-\mathrm{InAsSbP}-1.5 \mu \mathrm{m}, \mathrm{Zn}$ doping using diethylzinc as a source was done for $\mathrm{p}-\mathrm{n}$ junction creation. For the improvement of photodiode operating parameters it was important to reduce concentration of charge carriers in the active area, that was achieved by the charge carriers compensation due to the diffusion of the acceptor impurity $(\mathrm{Zn})$. It was found that distribution of concentration inside the active area and $\mathrm{p}$-n junction position were influenced by the flux of diethylzinc $\mathrm{F}_{\text {DeZn }}$ which was varied from $0.20 \mu \mathrm{mol} / \mathrm{min}$ to $0.27 \mu \mathrm{mol} / \mathrm{min}$. The obtained data is presented in the table 1 .

Table 1. The data for $3 \mathrm{mkm}$ photodiodes.

\begin{tabular}{|c||c||c|c||}
\hline Parameters / PD plate & 1 & 2 & 3 \\
\hline Ro, kOM, U(-10 mV) & 0.77 & 0.71 & 1.10 \\
\hline \hline Idark, $\mu \mathrm{A}(-100 \mathrm{mV})$ & 90 & 80 & 66 \\
\hline $\mathrm{C}, \mathrm{pF}(-10 \mathrm{mV})$ & 750 & 650 & 650 \\
\hline Responsitivity & 1.27 & 1.23 & 1.59 \\
\hline $\mathrm{D}^{*}(3,3 \mathrm{mkm}), \mathrm{cm} \sqrt{\mathrm{Hz}} / \mathrm{W}$ & $1.2 \times 10^{10}$ & $1.0 \times 10^{10}$ & $1.4 \times 10^{10}$ \\
\hline \hline $\mathrm{N}, \mathrm{cm}^{-3}$ & $1.5 \times 10^{17}$ & $6.0 \times 10^{16}$ & $2.2 \times 10^{16}$ \\
\hline \hline $\mathrm{F}_{\text {DeZn }}, \mu \mathrm{mol} / \mathrm{min}$ & 0.20 & 0.23 & 0.27 \\
\hline
\end{tabular}

Experimentally $\mathrm{C}-\mathrm{V}$ characteristics were measured at room temperature (fig.3a). To evaluate the effective concentration of carriers $\mathrm{N}$ in an active area $\mathrm{C}-\mathrm{U}$ characteristics were transformed into coordinates $\mathrm{C}^{-2}-\mathrm{V}$ (fig.3b). The sharply asymmetrical p-n transition model was used:

\section{$\mathrm{N}=2 \mathrm{C}^{2}\left(\mathrm{~V}-\mathrm{V}_{\mathrm{D}}\right) / \mathrm{e} \varepsilon \varepsilon_{0} \mathrm{~S}^{2}$}

Here $S$ is $p$-n transition square, $\varepsilon=15.15$ is dielectric constant for InAs $\varepsilon_{0}=15.15$ is dielectric constant, e - electron charge. The height of the potential barrier $V_{D}$ was determined by cut-off value in voltage axis.

As a result the optimal growth conditions, namely, flux value of diethylzinc $\mathrm{F}_{\text {DeZn }}$ were defined, minimum concentration of charge carriers as much as $2.2 \times 10^{16} \mathrm{~cm}^{-3}$ was obtained at $\mathrm{F}_{\text {DeZn }}=$ $0.27 \mu \mathrm{mol} / \mathrm{min}$. Thus, the improved operating photodiodes parameters were achieved: responsivity $\mathrm{R}=1.5 \mathrm{~A} / \mathrm{W}$, resistivity (at no bias) $\mathrm{R}_{0}=1.1 \mathrm{kOhm}$, detectivity $\mathrm{D}^{*}=1.6 \times 10^{10}$ $\mathrm{cm} \sqrt{\mathrm{Hz}} / \mathrm{W}$, dark currents $\mathrm{I}=60 \mu \mathrm{A}$ (at reverse bias $100 \mathrm{mV}$ ), capacity $\mathrm{C}=0.6 \mathrm{nF}$. 


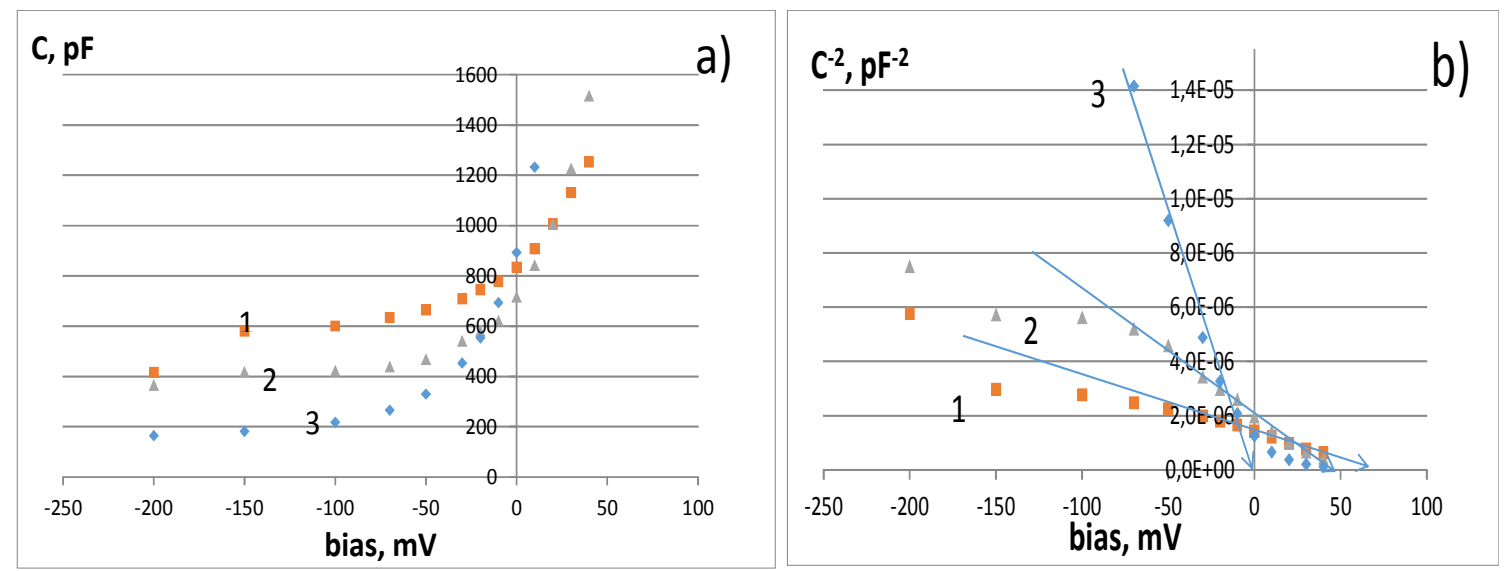

Figure 3: a) $C-V$ characteristics and b) $C^{-2}-V$ characteristics for $3 \mathrm{mkm}$ PDs. Numbers of the samples correspond to those pointed in table 1 .

\section{Conclusion}

Summarizing the performed investigations and obtained results, experiments necessary for creation of the smart IR module for express analysis of motor-car fuel were carried out. Transmission spectra of motor-car diesel fuel and petrol in the middle IR range were measured. Spectral particularities of different petrol brands were observed at wavelengths about $2.7-3.0$ $\mu \mathrm{m}$. Obtained results demonstrate a possibility for petrol analysis using optical cell based on an LED matrix and a PD. Epitaxial layers growth conditions were optimized for the improvement of the photodiode main operating parameters.

\section{References}

[1] www.lmsnt.com

[2] N.D. Stoyanov, B.E. Zhurtanov, A.P. Astakhova, A.N. Imenkov and Yu.P. Yakovlev, High-efficiency LEDs of 1.6-2.4 $\mu \mathrm{m}$ spectral range for medical diagnostics and environment monitoring, Semiconductors 37, 8, (2003) 971.

[3] N.D. Stoyanov, Kh.M. Salikhov, K.V. Kalinina, B.E. Zhurtanov, S.S. Kizhaev. Middle infrared LEDs: key element for new generation chemical sensors, Proceedings of the SPIE 8257, Optical Components and Materials IX, 82571E (2012). 